\title{
TEN-YEARS OF BARIATRIC SURGERY IN BRAZIL: IN-HOSPITAL MORTALITY RATES FOR PATIENTS ASSISTED BY UNIVERSAL HEALTH SYSTEM OR A HEALTH MAINTENANCE ORGANIZATION
}

\begin{abstract}
Dez anos de cirurgia bariátrica no Brasil: mortalidade intra-hopitalar em pacientes atendidos pelo sistema único de saúde ou
\end{abstract} por operadora da saúde suplementar

Silvana Márcia Bruschi KELLES, Carla Jorge MACHADO, Sandhi Maria BARRETO

From the Faculdade de Medicina da Universidade Federal de Minas Gerais (Medical School of the Minas Gerais Federal University), Belo Horizonte, MG, Brazil.

HEADINGS - Cirurgia bariátrica. Derivação gástrica. Mortalidade hospitalar. Tempo de permanência. Custos.
ABSTRACT - Background: Bariatric surgery is an option for sustained weight loss for the morbidly obese patient. In Brazil coexists the Unified Health System (SUS) with universal coverage and from which depend 150 million Brazilians and supplemental health security, predominantly private, with 50 million beneficiaries. Aim: To compare access, in-hospital mortality, length of stay and costs for patients undergoing bariatric surgery, assisted in one or another system. Methods: Data from DATASUS and IBGE were used for SUS patients' and database from one health plan of southeastern Brazil for the health insurance patients. Results: Between 2001 and 2010 there were 24,342 and 4,356 surgeries performed in SUS and in the health insurance company, respectively. The coverage rates for surgeries performed in 2010 were 5.3 and 91/100.000 individuals in SUS and health insurance respectively. The rate of in-hospital mortality in SUS, considering the entire country, was $0.55 \%, 0.44 \%$ considering SUS Southeast, and $0.30 \%$ for the health insurance. The costs of surgery in the SUS and in the health insurance trend to equalization over the years. Conclusion: Despite differences in access and characteristics that may compromise the outcome of bariatric surgery, patients treated at the Southeast SUS had similar rate of in-hospital mortality compared to the health insurance patients.

\section{Correspondence:}

Silvana Márcia Bruschi Kelles

Email: silvanakelles@gmail.com

Financial source: none

Conflicts of interest: none

Received for publication: 08/05/2014 Accepted for publication: 14/08/2014

DESCRTORES - Cirurgia bariátrica. Derivação gástrica. Mortalidade hospitalar. Tempo de permanência. Custos..
RESUMO - Racional: A cirurgia bariátrica é uma opção de perda de peso sustentada para o indivíduo obeso mórbido. No Brasil coexistem o Sistema Único de Saúde, de cobertura universal do qual dependem 150 milhões de brasileiros e a saúde suplementar, de caráter predominantemente privado, com 50 milhões de beneficiários. Objetivo: Comparar acesso, mortalidade intra-hospitalar, tempo de permanência e custos para pacientes submetidos à cirurgia bariátrica, assistidos por um ou outro sistema. Métodos: Foi utilizado o sistema TabNet do DATASUS e IBGE para pacientes SUS e banco de dados de uma operadora da região sudeste do Brasil para a saúde suplementar. Resultados: Entre 2001 e 2010 foram 24.342 e 4.356 operações pelo SUS e operadora, respectivamente. Taxas operatórias realizadas em 2010 foram de 5,3 e 91/100.000 indivíduos no SUS e na operadora na saúde suplementar respectivamente. A taxa de mortalidade intra-hospitalar no SUS, considerando todo o Brasil, foi de $0,55 \%$, na região sudeste $0,44 \%$, e na operadora $0,30 \%$. Os custos das operações no SUS e na saúde suplementar tendem à equiparação ao longo dos anos. Conclusão: Apesar da diferença no acesso e de características que podem comprometer o resultado da cirurgia bariátrica, os pacientes atendidos no SUS da região sudeste tiveram taxa de mortalidade intra-hospitalar semelhante aos da saúde suplementar.

INTRODUCTION

$\mathrm{O}$ besity has increased in Brazil in recent years, matching trends in developed countries. The Family Budget Survey 2008/2009 (Pesquisa de Orçamentos Familiares or POF 2008/2009) showed that the percentage of overweight individuals (body mass index or BMI $\geq 25 \mathrm{~kg} / \mathrm{m}^{2}$ ) aged over 20 years was $50.1 \%$ for males and $48.0 \%$ for females. For class I obese subjects $\left(B M I \geq 30 \mathrm{~kg} / \mathrm{m}^{2}\right.$ ) these percentages were $12.5 \%$ for males and $16.9 \%$ for females ${ }^{1}$. Unpublished data have shown that the prevalence of class II obesity (BMI between 35 and $40 \mathrm{~kg} / \mathrm{m}^{2}$ ) is $2.8 \%$, of class III or morbid obesity (BMI between 40 and $50 \mathrm{~kg} /$ $\mathrm{m}^{2}$ ) is $0.7 \%$, and of superobesity $\left(\mathrm{BMI} \geq 50 \mathrm{~kg} / \mathrm{m}^{2}\right.$ ) is $0.04 \%$ (Family Budget Survey 2008/2009 - unpublished data). In absolute numbers, it has been estimated that there will be 1.2 million morbidly obese individuals in Brazil in 2013. In the general population, the percentage of morbid obesity among women is $1 \%$; among men it is $0.4 \%$. A further concern is that $33.5 \%$ of children aged from 5 to 9 years, and $21.5 \%$ of youths aged from 10 to 19 years are overweight ${ }^{12}$. Obesity raises the mortality rate and is an independent risk factor for cardiovascular disease, arterial 
hypertension, and type II diabetes mellitus. The risk of early death doubles in morbidly obese patients compared to class II obese individuals ${ }^{2}$. Public health measures to contain the growing rates of obesity are in the agenda of government decision-makers in Brazil22. Meanwhile, perspectives for sustained or long term weight loss by conservative treatment among morbidly obese individuals is discouraging. Lifestyle changes and nutrition approaches fail in over $90 \%$ of cases in this group of people ${ }^{28}$.

Another approach for sustained weight loss is bariatric surgery, which can be done using several techniques by laparotomy or laparoscopy, with varying rates of success. The Brazilian Universal Health System (Sistema Único de Saúde or SUS) has provided this procedure in the public healthcare system since 2000 . The privately paid supplementary healthcare network in Brazil is required by law, since 2000, to provide bariatric surgery. The National Household Sampling Survey (Pesquisa Nacional por Amostra de Domicilios or PNAD) showed that the percentage of individuals with at least one health insurance plan was $25.9 \%$ (or 49.2 million people) in 2008 . This survey also revealed that there was an association between income level and having an insurance plan. Health insurance coverage ranged from $6.4 \%$ among people with a monthly household income level below half a minimum salary to $82.5 \%$ among individuals earning more than five minimum salaries, which shows a linear relationship between purchasing power and buying health insurance ${ }^{11}$.

Besides their social and economic profile, the ease of accessing bariatric surgery differs between users of HMOs and of the SUS (150 million Brazilians use only the latter). There is a long waiting line for bariatric surgery among SUS patients; there are few authorized centers, which are unable to meet the demand for this procedure. Waiting times for bariatric surgery through the SUS ranges from 2.2 years ${ }^{21,30}$ to 3.4 years $^{15}$. Such a long waiting time suggests that patients using the SUS have a different profile compared to patients with health insurance plans, for whom there is no waiting time; patients are only required to meet eligibility criteria for bariatric surgery ${ }^{7}$. Additionally, the health of patients who are required to wait longer may deteriorate, thereby affecting preoperative conditions and postoperative outcomes in patients operated within the SUS compared to patients who have health insurance plans.

The purpose of this study was to assess whether inhospital mortality due to bariatric surgery differs between a cohort of patients with care delivered by the SUS and a cohort of patients with care delivered by a health insurance plan, and to discuss - based on indirect data - which factors, if any, may influence these results. An assumption is that all patients in these cohorts meet the medical criteria for bariatric surgery.

\section{METHODS}

The research ethics committee of the Minas Gerais Federal University approved this study (no. COEP UFMG ETIC 0074.0.203.000-11).

This study consisted of a historical nonconcurrent assessment of patients undergoing gastric bypass surgery by laparotomy for the treatment of morbid obesity, with the aim of comparing patients whose treatment was paid by the SUS and patients whose treatment was paid by a supplementary health insurance plan of an $\mathrm{HMO}$ in the city of Belo Horizonte. Population estimates were taken from the IBGE (Brazilian Geography and Statistics Institute) 2010 demographic census ${ }^{10}$.

Information on SUS patients was based on data gathered from the Informatics Department of the Unified
Health System (Departamento de Informática do Sistema Único de Saúde or DATASUS) and its Hospital Information System (Sistema de Informações Hospitalares or SIH) (abridged data). DATASUS operates within the Brazilian Ministry of Health; it gathers and consolidates data on hospital admittances paid for by the SUS, including the procedures that were carried out - the code of each procedure, mean hospital stays, and the costs for each region, state or city. Data was gathered for the period from January 2001 to December 2007 on the following procedures and codes: gastroplasty (33.022.04-6); vertical banded gastroplasty (33.022.12-7); Roux-en-Y gastroplasty (33.022.13-5); and gastrectomy with or without a duodenal switch (33.022.14-3). From January 2008 to December 2010, codes for the payment of bariatric surgery became: gastrectomy with or without a duodenal switch (040701012-2); Roux-en-Y gastroplasty (040701017-3); and vertical banded gastroplasty (040701018-1). The number of procedures that were carried out, the codes, the total cost, the total number of hospital stays per year, the number of in-hospital deaths, gender and age were taken from the SIH (SUS) database. Data on the BMI and comorbidities are not available in the SUS database. Data on supplementary healthcare coverage for Brazil was gathered from the DATASUS website.

Data on procedures carried out by the $\mathrm{HMO}$ in Belo Horizonte were used to estimate the hospital stay, the cost and the mortality of patients within the same period. The administrative database of the HMO yielded information about the procedure, the hospital stay, costs, and inhospital deaths by age and gender. This database also had data on the BMI and comorbidities at the time of surgery.

Laparotomy was the access route for gastroplasty for both SUS and HMO patients during the study period.

Cost values are presented historically (uncorrected for inflation) for comparison between the SUS and the HMO. Costs for the SUS and the HMO included payments to physicians, hospital fees, tariffs, hospital materials and drugs, and the cost of complications, if any.

In-hospital mortality for both cohorts was considered as death occurring during the postoperative period after bariatric surgery before discharge. Data on death after hospital discharge at any time were not available.

The surgical criteria were the same for both the SUS and the HMO cohorts, namely: stable obesity for at least five years; prior regular medical therapy for at least two years, which was considered ineffective; and a body mass index $(B M I) \geq 40 \mathrm{~kg} / \mathrm{m}^{2}$ or a BMI between 35 and $39.9 \mathrm{~kg} / \mathrm{m}^{2}$ with life-threatening organic or psychosocial comorbidities resulting from or worsened by obesity. Other prerequisites were: age from 18 to 65 years; an understanding by the patient and by family members of the risks and consequences of surgery and post-operative therapy; and ongoing family support. Bariatric surgery was contraindicated in the following cases: obesity due to endocrine conditions; young patients in which long bone epiphyseal closure was incomplete; individuals with moderate or severe psychosis or dementia; individuals with a recent history of a attempted suicide; drug abusers (alcohol or other illegal drugs) ${ }^{1}$. The procedure was available for both SUS and HMO patients, generally a Roux-en-Y gastric bypass by laparotomy.

\section{Statistics}

The arithmetic mean of days in hospital, the annual mean cost, the cost per day in hospital, the mortality rate (number of deaths divided by the number of patients operated), and the mortality rate per patient/day (number of deaths divided by the total number of patients/day in hospital) were calculated for both cohorts. Data on the 
duration of hospitalization for patients with care delivered by the HMO were only available after 2004. The Student $t$ test and the chi-square test were applied to study respectively the means and the proportions of SUS and HMO patients in Brazil and in Southeast Brazil.

The coverage rate of the SUS for bariatric surgery was estimated based on IBGE data for the Brazilian population aged from 18 to 60 years, for each region of the country, during the study period. The denominator was the Brazilian population for each region minus the number of people covered by supplementary health insurance for each region and year to adjust the eligible population for bariatric surgery covered by the SUS and to avoid overestimating the demand. The rate of surgery among HMO-covered patients was found by dividing the number of operated patients by the number of covered patients in the same age range and study period. The mortality rate for each cohort was found by dividing the number of deaths by the number of operated patients during the study period; the relative risk (RR) was found by dividing these rates, and was used for comparison purposes.

The chi-square test was applied to find the general mortality; the sample size yielded an $80 \%$ power with a $10 \%$ type alpha error. There was not enough statistical power to analyze the mortality per subgroup because there were few deaths (it was a rare event) ${ }^{16}$. Thus, only a descriptive analysis was made of subgroup data, with no further statistical test.

A comparison of costs was made based on the total cost of the cohort per year and the cost per day. The total cost was divided by the total number of hospital stays (in days) during the time period.

The SATA version 12 software was used for calculations.

\section{RESULTS}

There were 24,342 bariatric surgery procedures undertaken by the SUS in Brazil between January 2001 and December 2010; of these 10,268 were carried out in Southeast Brazil. During the same time frame, 4,356 procedures were done on patients covered by the HMO.

The number of procedures on SUS patients has increased countrywide from $0.65 / 100.000$ people (2001) to $5.23 / 100.000$ people (2010) for patients aged from 18 to 60 years. This increase was particularly significant in South Brazil where it reached $18.8 / 100.000$ people in 2010. Bariatric surgery among HMO patients went from $48 / 100.000$ to $91 / 100.000$ people in the same time period among patients aged over 18 years.

The percentage of patients aged below 50 years was significantly higher among $\mathrm{HMO}$ patients compared to SUS patients. Table 1 shows the distribution, characteristics and deaths of SUS and HMO patients from 2001 to 2010.

Age and gender data revealed that the mean age remained stable among SUS patients but decreased by four years among HMO patients between 2001 and 2010. The percentage of male patients covered by the SUS that underwent surgery decreased four percentage points during the same time frame (Figure 1).
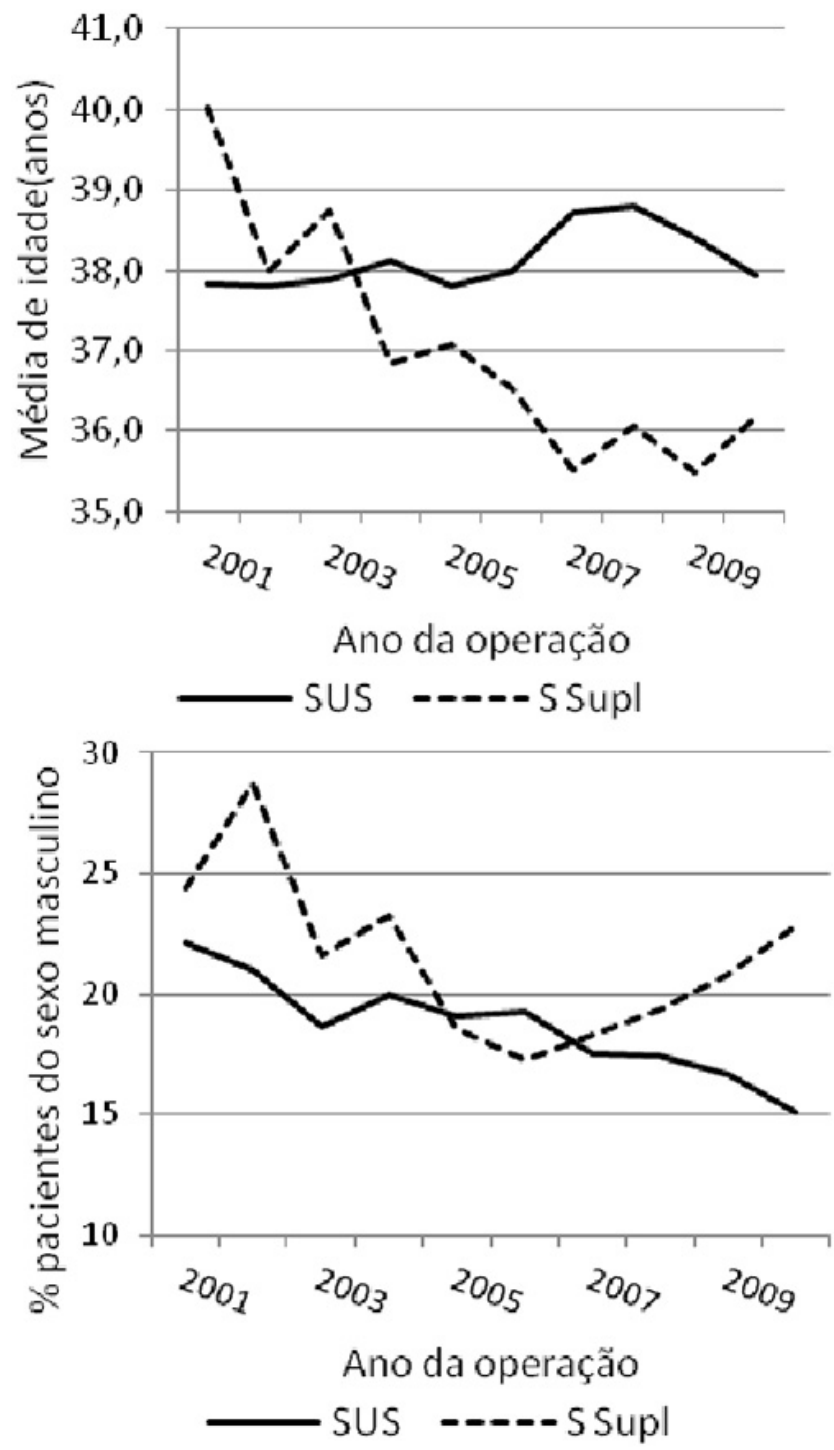

Figure 1 - Mean hospital stay in SUS-covered patients (Brazil and Southeast Brazil) and HMO-covered patients (supplementary healthcare) from 2001 to 2010

The BMI and comorbidities (arterial hypertension, diabetes, joint diseases, and sleep apnea) had been registered for HMO patients, but not for SUS patients. The mean BMI among HMO-covered patients decreased during the study period (Figure 2).

TABLE 1 - Characteristics of patients undergoing bariatric surgery by the SUS and an HMO from 2001 to 2010

\begin{tabular}{|c|c|c|c|c|}
\hline Variable & SUS Brazil & SUS Southeast Region & $\begin{array}{c}\text { HMO (supplementary } \\
\text { healthcare) }\end{array}$ & $\begin{array}{c}\text { SUS Southeast } x \mathrm{HMO} \\
\mathrm{P} \text { value }\end{array}$ \\
\hline Number of procedures & 24,342 & 10,268 & 4,356 & - \\
\hline Mean age (SD) in years & $38.2(10.4)$ & $38.9(10.5)$ & $36.2(10.5)$ & $<0.001$ \\
\hline$\%$ age $\geq 18<50$ years & 83.8 & 81.5 & 86.8 & $<0.001$ \\
\hline$\%$ age $\geq 50<60$ years & 15.1 & 16.3 & 10.7 & $<0.001$ \\
\hline$\%$ age $\geq 60$ years & 1.1 & 2.2 & 2.4 & 0.460 \\
\hline Males (\%) & 17.8 & 18.5 & 20.7 & $<0.001$ \\
\hline Mean hospital stay in days (SD) & $6.1(0.8)$ & $6.2(0.6)$ & $3.3(0.2)$ & $<0.001$ \\
\hline Number of deaths & 133 & 45 & 13 & \\
\hline $\begin{array}{l}\text { Mortality rate (per } 1000 \\
\text { procedures) }\end{array}$ & 5.5 & 4.4 & 3.0 & 0.210 \\
\hline
\end{tabular}




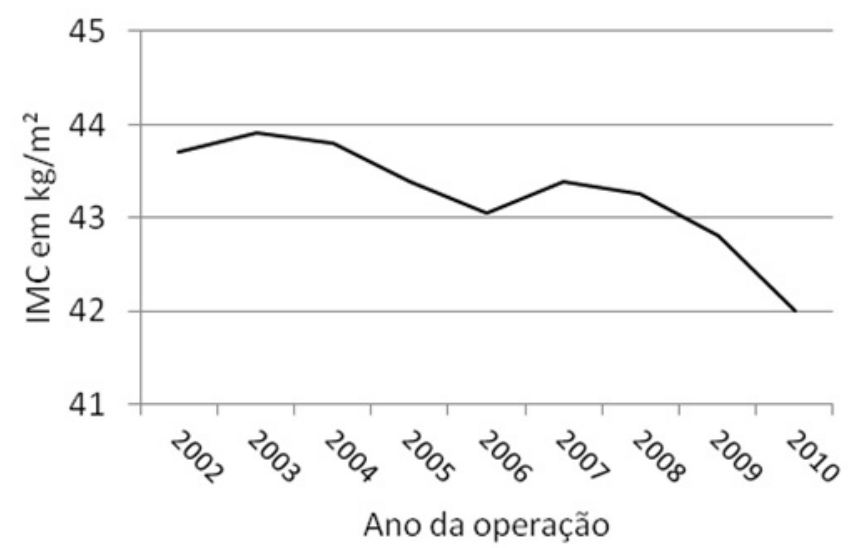

FIGURE 2 - Variation of the mean BMI in patients covered by health insurance (HMO) undergoing bariatric surgery from 2002 to 2010

The in-hospital mortality rate was 5.5 per 1,000 operated cases among patients covered by the SUS in Brazil. It was 3.0 per 1,000 operated cases among patients covered by a HMO. The gross relative risk was 1.84 (CI 95\%; 1.04-3.20). The mortality rate was 4.4 per 1,000 operated cases among SUS-covered patients in Southeast Brazil; in this case, the relative risk was 1.47 (CI 95\%; 0.79-2.72) compared to the death rate of $\mathrm{HMO}$-covered patients (Table 2).

The mortality rate among SUS-covered patients decreased during the study period from $8 / 1,000$ procedures in 2002 to $4 / 1,000$ in 2010 . The mortality rate did not change among $\mathrm{HMO}$-covered patients.

The mean hospital stay fell nearly $50 \%$ among SUScovered patients during the study period but remained stable for HMO-covered patients. The hospital stay was statistically longer among SUS-covered patients (Brazil and Southeast Brazil) compared to HMO-covered patients $(p<0.0001)$ (Figure 3).

The in-hospital mortality rate per 1,000 patients/ day-in-hospital was 0.9 (133 deaths/147.122 patients/ day-in-hospital) among SUS-covered patients in Brazil and 0.7 in Southeast Brazil (45 deaths/64,083 patientsday). The mortality rate for HMO-covered patients (data is available from 2004 onwards) was 0.9/1,000 patients-day (12 deaths/13,227 patients-day).

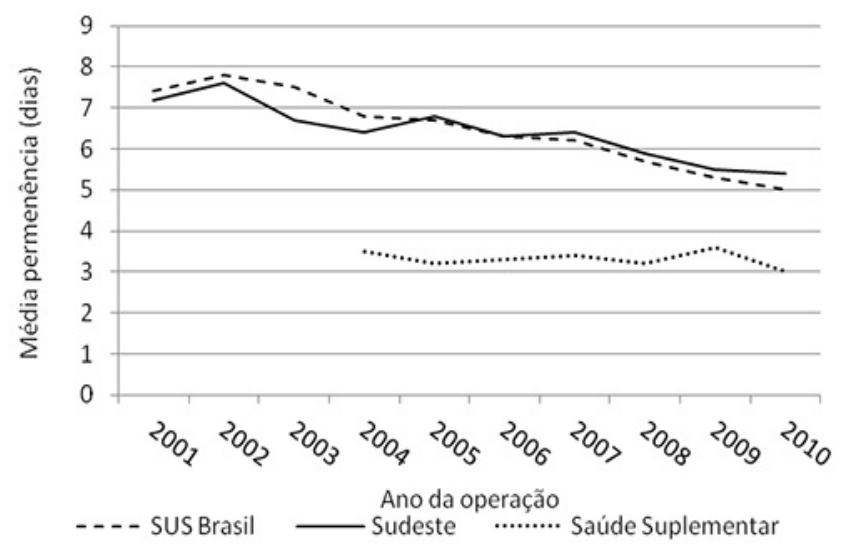

FIGURE 3 - Mean hospital stay in SUS-covered patients (Brazil and Southeast Brazil) and HMO-covered patients (supplementary healthcare) from 2001 to 2010

The historical value of the mean hospital stay for SUS-covered patients undergoing bariatric surgery more than doubled throughout the study period. The historical value of the mean hospital stay for $\mathrm{HMO}$-covered patients remained stable during the same period. The comparison of payments in 2004 showed that the values expended by SUS corresponded of half of the ones expended by the HMO. This proportion changed through the study period, and expenditures in SUS were $80 \%$ of the value expended by the HMO in 2010. Considering that the mean hospital stay was two times in SUS, the mean cost per day for SUS ranged from one quarter to half of the cost observed in the HMO-covered patients, between 2004 and 2010 (Table 3).

Table 4 presents anthropomorphic data and comorbidities of HMO and the profile of SUS patients according to data gathered from a systematic review ${ }^{14}$ for the study period. Differences in means and proportions were significant for all study variables, showing that the anthropomorphic profiles and comorbidities differ in the two cohorts; it is unfavorable for SUS patients from the perspective of a prognosis.

TABLE 2 - Number of procedures, deaths and mortality rates among SUS-covered patients per region in Brazil, and among HMO-covered patients

\begin{tabular}{|c|c|c|c|c|c|c|c|c|c|c|c|c|}
\hline Region and site of care & 2001 & 2002 & 2003 & 2004 & 2005 & 2006 & 2007 & 2008 & 2009 & 2010 & Total & $\begin{array}{l}\text { Mortality rate } \\
\text { (\%) }\end{array}$ \\
\hline SUS North (n) & 53 & 60 & 58 & 50 & 66 & 81 & 105 & 50 & 62 & 40 & 625 & \\
\hline Deaths (n) & 0 & 1 & 1 & 0 & 1 & 0 & 0 & 1 & 0 & 1 & 5 & 0.80 \\
\hline SUS Northeast (n) & 23 & 69 & 208 & 182 & 285 & 260 & 253 & 375 & 437 & 413 & 2,505 & \\
\hline Deaths (n) & 1 & 0 & 0 & 0 & 1 & 1 & 0 & 2 & 0 & 0 & 4 & 0.20 \\
\hline SUS Central-West (n) & 0 & 27 & 158 & 112 & 131 & 167 & 146 & 132 & 176 & 161 & 1,210 & \\
\hline Deaths (n) & 0 & 0 & 4 & 3 & 1 & 0 & 3 & 0 & 1 & 2 & 14 & 1.16 \\
\hline SUS Southeast (n) & 365 & 601 & 812 & 940 & 944 & 1,200 & 1,379 & 1,245 & 1,284 & 1,498 & 10,268 & \\
\hline Deaths (n) & 0 & 6 & 3 & 7 & 4 & 5 & 9 & 2 & 3 & 6 & 45 & 0.44 \\
\hline SUS South (n) & 56 & 251 & 542 & 588 & 840 & 820 & 1.095 & 1.393 & 1.772 & 2,377 & 9,734 & \\
\hline Deaths (n) & 1 & 1 & 3 & 7 & 5 & 11 & 11 & 10 & 7 & 8 & 64 & 0.66 \\
\hline SUS Brazil (n) & 497 & 1,008 & 1,778 & 1,872 & 2,266 & 2,528 & 2,978 & 3,195 & 3,731 & 4,489 & 24,342 & \\
\hline Deaths (n) & 2 & 8 & 11 & 17 & 12 & 17 & 23 & 15 & 11 & 17 & 133 & \\
\hline $\begin{array}{l}\text { SUS Brazil - mortality } \\
\text { rate }(\%)\end{array}$ & 0.40 & 0.79 & 0.62 & 0.91 & 0.53 & 0.67 & 0.77 & 0.47 & 0.29 & 0.38 & & 0.55 \\
\hline $\mathrm{HMO}(\mathrm{n})$ & 197 & 87 & 564 & 378 & 484 & 412 & 480 & 590 & 534 & 630 & 4,356 & \\
\hline Deaths (n) & 0 & 0 & 0 & 3 & 2 & 3 & 0 & 3 & 1 & 1 & 13 & \\
\hline $\begin{array}{l}\text { Supplementary healthcare } \\
\text { - mortality rate (\%) }\end{array}$ & 0.00 & 0.00 & 0.00 & 0.79 & 0.41 & 0.73 & 0.00 & 0.51 & 0.19 & 0.16 & & 0.30 \\
\hline
\end{tabular}


TABLE 3 - Historical value of the mean hospital stay and rate/day for bariatric surgery among SUS-covered patients (mean cost for Brazil and for Southeast Brazil) and for HMO-covered patients

\begin{tabular}{|c|c|c|c|c|c|c|}
\hline \multirow[b]{2}{*}{ Year } & \multicolumn{2}{|c|}{ SUS Brazil } & \multicolumn{2}{|c|}{ SUS Southeast Brazil } & \multicolumn{2}{|c|}{ HMO (supplementary healthcare) } \\
\hline & $\begin{array}{c}\text { Mean cost of } \\
\text { hospital stay }(R \$)\end{array}$ & $\begin{array}{l}\text { Mean cost/day in } \\
\text { hospital (R\$) }\end{array}$ & $\begin{array}{c}\text { Mean cost of } \\
\text { hospital stay (R\$) }\end{array}$ & $\begin{array}{c}\text { Mean cost/day in } \\
\text { hospital (R\$) }\end{array}$ & $\begin{array}{c}\text { Mean cost of } \\
\text { hospital stay }(R \$)\end{array}$ & $\begin{array}{l}\text { Mean cost/day in } \\
\text { hospital (R\$) }\end{array}$ \\
\hline 2001 & $2,490.22$ & 336.52 & $2,441.43$ & 339.09 & NA & NA \\
\hline 2002 & $2,918.35$ & 374.15 & $2,857.28$ & 375.96 & NA & NA \\
\hline 2003 & $3,211.30$ & 428.17 & $3,128.04$ & 466.87 & NA & NA \\
\hline 2004 & $3,229.16$ & 474.88 & $3,135.94$ & 489.99 & $6,906.32$ & $1,973.23$ \\
\hline 2005 & $3,272.35$ & 488.41 & $3,154.79$ & 463.94 & $6,989.02$ & $2,184.07$ \\
\hline 2006 & $3,220.60$ & 511.21 & $3,122.61$ & 495.65 & $7,048.14$ & $2,135.80$ \\
\hline 2007 & $3,448.65$ & 556.23 & $3,439.67$ & 537.45 & $7,114.23$ & $2,092.42$ \\
\hline 2008 & $4,925.31$ & 864.09 & $4,819.30$ & 816.83 & $6,862.35$ & $2,144.48$ \\
\hline 2009 & $5,446.52$ & $1,027.65$ & $5,291.81$ & 962.15 & $6,792.66$ & $1,886.85$ \\
\hline 2010 & $5,467.99$ & $1,093.60$ & $5,321.63$ & 985.49 & $6,825.13$ & $2,275.04$ \\
\hline
\end{tabular}

NA - Not available.

TABLE 4 - Characteristics of patients undergoing bariatric surgery in $\mathrm{HMO}$-covered and SUS-covered patients based on available data* and estimated according to a systematic review, from 2001 to $2010^{* *}$

\begin{tabular}{|c|c|c|c|}
\hline Parameter & $\begin{array}{c}\text { Patients covered by } \\
\text { the SUS }\end{array}$ & $\begin{array}{c}\text { Patients covered by the } \\
\text { HMO }\end{array}$ & $\begin{array}{c}\text { Difference of means/ } \\
\text { proportions (CI 95\%) }\end{array}$ \\
\hline Age in years (mean and CI 95\%) & $38.2(38.1-38.3)^{\star}$ & $36.7(36.4-37.0)$ & $1.5(1.2-1.9)$ \\
\hline Males (\% and CI 95\%) & $17.8(17.3-8.25)^{\star}$ & $20.7(19.5-22.0)$ & $2.9(1.6-4.2)$ \\
\hline BMI in kg/m (mean and CI 95\%) & $49.3(47.8-50.8)^{\star \star}$ & $43.3(43.2-43.5)$ & $6.0(5.7-6.4)$ \\
\hline Arterial hypertension (\% and CI 95\%) & $47.4(44.8-0.1)^{\star *}$ & $39.6(38.2-41.1)$ & $7.8(4.8-10.8)$ \\
\hline Diabetes (\% and CI 95\%) & $17.3(15.4-9.4)^{\star *}$ & $12.1(11.2-13.2)$ & $5.2(3.0-7.5)$ \\
\hline Arthropathy (\% and CI 95\%) & $21.1(18.8-23.6)^{\star *}$ & $13.8(12.9-14.9)$ & $7.3(4.7-10.0)$ \\
\hline Sleep apnea (\% and CI 95\%) & $14.6(12.6-16.8)^{\star *}$ & $6.4(5.7-7.2)$ & $8.2(6.1-10.6)$ \\
\hline
\end{tabular}

Source of data: ${ }^{\text {SIH SUS }}$ ** Reference $^{14}$

\section{DISCUSSION}

A low in-hospital death rate after bariatric surgery among patients covered by the SUS and an HMO shows that this is a low-risk procedure in the short term. The in-hospital mortality rate among SUS-covered patients in Brazil was $84 \%$ higher than that of patients covered by supplementary healthcare (HMO); the rate, however, was similar between SUS-covered patients in Southeast Brazil and HMO-covered patients. Mortality adjusted for the duration of hospital stay was similar between SUS and HMO patients, because the mean hospital stay of SUS-covered patients was about twice that of HMO-covered patients. A time trend analysis shows a consistent fall in the mortality rate for both SUS and HMO patients; this was more evident among SUS-covered patients, bringing both rates closer across the study period. Such a decrease may reflect the growing experience of surgeons and hospital teams with the postoperative care of bariatric surgery patients. ${ }^{13,26}$ Brazilian and international data on in-hospital mortality after bariatric surgery has ranged from 0.5 to $3.6 \%$ in non-laparoscopic procedures within the past 10 years; most papers have published a value closer to $0.5 \%$. Massomi et al ${ }^{17}$ found an in-hospital mortality rate of $0.52 \%$ among 42,591 patients in the United States undergoing non-laparoscopic bariatric surgery between 2006 and 2008. Padwal (2005) reported a $0.5 \%$ death rate among 1,100 patients operated in 2002 and 2003 in Canada. ${ }^{24}$ The mortality rate for 2005 was $0.32 \%$ among 4,040 patients (laparotomy gastric bypass) in Chile. ${ }^{5}$ Santo et al, in Brazil, reported a $0.55 \%$ mortality rate in a retrospective survey of 538 patients operated between 2006 and 2011 at the Clinic Hospital, São Paulo University. ${ }^{24}$ Diniz et al found a higher rate $(3.6 \%)$ in a cohort operated in the city of Belo Horizonte from 1998 to $2005 .^{6}$ Thus, in-hospital mortality rates of SUS-covered patients in Brazil (0.55\%) and in Southeast Brazil (0.44\%), and HMO-covered patients (0.33\%) are similar to the best published results, which suggests that a longer access time for surgery (in the case of SUS patients) does not alter the risk of in-hospital death.
Possibly HMO-covered patients stay less in hospital because their access to preoperative tests and assessments is easier compared to SUS-covered patients. Salgado $\mathrm{Jr}^{23}$ reported that SUS patients at his unit were admitted to hospital six days before surgery for lab tests and a multiprofessional evaluation. A consistent fall in the hospital stay of SUScovered patients has been noted - from 7.4 days in 2001 to 5 days in 2010.

Age and gender are the only verified factors that may directly affect in-hospital morbidity/mortality in the study cohorts. The percentage of male patients covered by the SUS undergoing bariatric surgery decreased during the study period. A few authors have suggested that being male is a risk factor for postoperative death following bariatric surgery ${ }^{29}$; such a decrease among men may reduce the mortality rate.

The mean age of operated SUS patients was nearly three years higher compared to HMO-covered patients, which may alter the risk of surgery positively for the $\mathrm{HMO}$. The frequency of HMO patients aged below 50 years was significantly lower compared to SUS patients. There was no statistically significant difference between the cohorts among patients aged 60 years or over. The mean age of SUS patients remained stable, whereas it decreased among HMO patients. Such a decrease has not been reported in the literature; on the contrary, published results have shown an increase in the mean age of operated patients. ${ }^{25}$

Unfortunately the BMI and comorbidities of SUScovered patients was not reported. A systematic review ${ }^{14}$ suggests that these patients have a higher BMI and more comorbidities - arterial hypertension, diabetes and sleep apnea - all of which are associated with a higher operative and postoperative mortality. The mean BMI at surgery has decreased each year in $\mathrm{HMO}$-covered patients. A lower mean $\mathrm{BMI}$ and age certainly have a positive effect on the operatory mortality rate.

The SUS is the main paying agent of hospital admittances in Brazil. Information on hospital admittances comprises the Hospital Information System of the SUS (SIH/SUS). Data is gathered from Hospital Admittance Authorization forms 
$(\mathrm{AIH})$, processed and made available nationally. The $\mathrm{AIH}$ includes several variables, namely: identification, description of the hospital, cash paid for hospital admittance, the nature of the medical event, the hospital stay, and the patient's outcome or reason for leaving the hospital. Hospitals use this form to write the invoice, which is generated according to a table published by the SUS to calculate the amount paid for procedures 4 .

In the present study, the cost of bariatric surgery consisted only of historical values of hospital stays, since the aim was to compare the cost of hospital admittances year by year between both cohorts. The cost per day of an $\mathrm{HMO}$-covered patient was four times higher than that of SUScovered patients in 2004; this difference, however, decreased across the study period. It is worth noting that the duration of hospital stays of SUS patients fell during the study period. Thus, the mean cost per day of hospitalization of SUS patients is less than half that of $\mathrm{HMO}$ patients if we consider that the hospital stay was nearly double for SUS patients. A further point to consider is that SUS accounts may be invoiced at lower values, thereby underreporting the costs.

In this study were only able to estimate the true coverage of the SUS by calculating it for 100,000 inhabitants/year. There are two healthcare systems in Brazil, as follows: universal coverage by the SUS, and supplementary healthcare (HMO) for individuals that are able to pay for health insurance or are fully employed by companies that provide health insurance plans. The coverage rate of supplementary health has increased in Brazil between 2001 and 2010 for individuals aged 20 years or above (from $20.8 \%$ to $24.8 \%$ ). Because HMO-covered patients can access bariatric surgery more easily, estimates of the population eligible for SUS coverage only exclude the number of individuals with health insurance from the general population that may seek SUS healthcare (denominator). Thus, while the total rate of coverage of bariatric surgery by the SUS may be underestimated because the denominator is likely to be less accurate, the rate of surgery undertaken by the HMO may be overestimated because of "moral hazard" pressures. Several individuals hire health insurance after they have acquired morbid obesity in order to be operated. In the present study, about $20 \%$ of patients undergoing bariatric surgery had hired the health insurance plan one year before surgery. Thus, any comparison between rates of surgery in both systems is inadequate because each system has its own peculiarities. The rate of the SUS can be used to compare its ability to provide care with that of other universal systems. The National Institute for Health and Care Excellence (NICE) ${ }^{18}$ has estimated that 10 bariatric surgeries per 100,000 inhabitants were needed in 2012, which is twice the current number among SUS-covered patients in Brazil; the population of morbidly obese patients in that year - one million individuals - was similar to that in Brazil ${ }^{9}$. The rate of bariatric surgeries in the United States was 63.9/100,000 adults in 2004, falling to $54.2 / 100,000$ in $2008^{19}$. The estimated number of morbidly obese patients in the US in 2012 was 15.5 million persons ${ }^{27}$.

The waiting time for bariatric surgery for SUS patients ranges from one to four years $6,15,21,30$. The mean waiting time for this procedure in Canada (2011), which has universal healthcare and 0.8 million morbidly obese patients ${ }^{8}$, was 5.2 years $^{3}$. It appears, therefore, that these patients covered by universal healthcare in Canada face similar difficulties to those in Brazil. Meanwhile, HMO-covered patients enjoy near immediate access if they meet eligibility criteria.

This study has other limitations besides an imprecise estimate of coverage. The most important is having only aggregate data from the SUS. Calculating the number of procedures that were actually done is another limitation of this study. Although the number of operations is available and accurate, the denominator - the population that counts only on the SUS - was only estimated, and the number of patients with supplementary healthcare was deduced from this number. Numbers may be less than accurate because there are several modes of supplementary healthcare, not all of which provide hospital admittance. Even so, rates may be presented to estimate the order of magnitude of the differences. Another limitation of this study is that relevant data, such as comorbidities among SUS patients, are not available. Finally, data on patients covered by the HMO may not reflect the reality of supplementary healthcare as a whole in Brazil.

\section{CONCLUSIONS}

In-hospital mortality after bariatric surgery is a rare event. The numbers for both cohorts concur with other published results from developed countries and for laparotomy as the access route. The rate of in-hospital mortality was similar in $\mathrm{HMO}$-covered patients and in patients covered by the SUS in Southeast Brazil, even though the latter face more difficulties in accessing this procedure and are a few years older.

If the rate of surgery for SUS-covered patients appears to fall below the demand, compared to internationally published results, the rate in supplementary healthcare is higher compared to that in several developed countries. Moral hazard may certainly explain part of this difference; other reasons require further study, such as over-prescription of surgery in supplementary healthcare. The long term consequences of a lower age and lower BMI at the time of surgery are not known.

\section{ACKNOWLEDGEMENTS}

The authors with to thank Unimed-BH for providing the data on the morbidity and mortality of its patients; also the team of librarians Mrs. Mariza Cristina Torres Talim and Mariana Fernandes Ribeiro; and to the Fundação de Amparo à Pesquisa do Estado de Minas Gerais (FAPEMIG) who funded this study. Project number: APQ-02241-10.

\section{REFERENCES}

1. Brasil. Ministério da Saúde. Portaria GM/MS n 196 de 29 de fevereiro de 2000. Brasília. Distrito Federal, 01 de março de 2000.

2. Calle EE, Thun MJ, Petrelli JM, Rodriguez C, Heath CW, Jr. Body-mass index and mortality in a prospective cohort of U.S. adults. N Engl J Med. 1999; 341:1097-1105.

3. Christou NV, Efthimiou E. Bariatric survey waiting time in Canada. Can J Surg 2009; 52(3):229-34

4. Cintra RF, Vieira SFA, Hall RJ, Fernandes CR. A informação do setor de faturamento como suporte à tomada de decisão. Cien Saude Coletiva. 2013;18(10):3043-53.

5. Csendes A, Maluenda F. Morbimortalidad de la cirugía bariátrica: Experiencia chilena en 10 instituciones de salud. Rev Chil Cir. 2006; 58(3): 208-212.

6. Diniz MFHS, Passos VMA, Barreto SM, Diniz MTC, Linares DB, Mendes LN. Perfil de pacientes obesos classe III do Sistema Público de Saúde, submetidos à gastroplastia em "Y de Roux" no Hospital das Clínicas da UFMG: altas prevalências de superobesidade, comorbidades e mortalidade hospitalar. Rev Med Minas Gerais 2008; 18(3):183-90.

7. Gastrointestinal surgery for severe obesity. Proceedings of a National Institute of Health Consensus Development Conference. [No authors listed]. Am J Clin Nutr 1992; 55(Suppl 2):615S-619S.

8. Gregory DM, Newbook JT, Twell LK. Patients' perceptions of waiting for bariatric surgery: a qualitative study. Int J Equity Health [Internet]. 2013 [acesso em out. 2013], 12:86 Disponível em http://www. equityhealthj.com/content/pdf/1475-9276-12-86.pdf

9. Health and Social Care Information Centre (UK) Health Survey for England. [Internet] Dec. 2012. [acesso em dez. 2013] Disponível em http://www.hscic.gov.uk/catalogue/PUB09300. 
10.Instituto Brasileiro de Geografia e Estatística (IBGE). Censo demográfico 2010. [acessoemago.2013] Disponívelem http://www. ibge.gov.br/home/estatistica/indicadores/trabalhoerendimento/ pnad_continua/default_analise.shtm

11.Instituto Brasileiro de Geografia e Estatística (IBGE). Pesquisa Nacional por Amostra de Domicílios 2008. [acesso em ago. 2013] Disponível em http://biblioteca.ibge.gov.br/visualizacao/ monografias/GEBIS\%20-\%20RJ/panorama.pdf.

12. Instituto Brasileiro de Geografia e Estatística. Pesquisa de Orçamentos Familiares 2008-2009: antropometria e estado nutricional de crianças, adolescentes e adultos no Brasil. Rio de Janeiro: IBGE; 2010 [acesso em mar. 2013]. Disponível em http:// www.ibge.gov.br/home/estatistica/populacao/condicaodevida/ pof/2008_2009_encaa/comentario.pdf.

13. Kelles SMB, Barreto SM, Guerra HL. Mortality and hospital stay after bariatric surgery in 2,167 patients: influence of the surgeon expertise. Obs Surg 2009; 19:1228-35.

14. Kelles SMB.Impacto em médio prazo da cirurgia bariátrica na utilização de serviços de saúde, morbi-mortalidade e custos com atenção médica. Belo Horizonte: Universidade Federal de Minas Gerais, Pós-Graduação em Ciências Aplicadas à Saúde do Adulto 2014. Available in http://www.bibliotecadigital.ufmg.br/dspace/ handle/1843/BUOS-9P8HR7

15. Khawali C, Ferraz MB, Zanella MT, Ferreira SRG. Evaluation of quality of life in severely obese patients after bariatric surgery carried out in the public healthcare system. Arq Bras Endocrinol Metabol 2012; 56(1): 33-38.

16. King G, Zeng L. Logistic regression in rare events data. Pol Analysis 2001;9(2):137-63.

17. Masoomi H, Nguyen NT, Satamos MJ, Smith BR. Overview of outcomes of laparoscopic and open Roux-en-Y gastric bypass in the United States. Surg Technol Int. 2012;22:72-6.

18. National Institute for Health and Care Excellence - NICE (UK) Assumptions used in estimating a population benchmark.[Internet] Mar. 2012 [acesso em dez. 2013] Disponível em http://www.nice.org. uk/usingguidance/commissioningguides/bariatric/assumptions.jsp
19. Nguyen NT, Massomi H, Magno CP, Nguyen XM, Laugenour K, Lane J. Trends in use of bariatric surgery, 2003-2008. J Am Coll Surg 2011;213(2):261-6.

20. Padwal RS. Characteristics of Patients Undergoing Bariatric Surgery in Canada. Obesity Research 2005; 13(2):2052-4

21. Petribu K; Ribeiro ES; Ollwira FM; Braz CI; Gomas ML; Araujo DE et al. Binge eating disorder in a population of morbid obese candidates to bariatric surgery at the Oswaldo Cruz University Hospital in Recife, PE. Arq Bras Endocrinol Metabol. 2006; 50(5): 901-8.

22. Reis CEG, Vasconcelos IAL, Barros JFN. Políticas públicas de nutrição para controle da obesidade infantil. Rev Paul Pediatr.2011; 29(4):625-33.

23. Salgado Jr W, Pitanga KC, Santos JS, Sankarankutty K, Silva Jr OC, Ceneviva R. Costs of bariatric surgery in a teaching Hospital and the financial support provided by the Public Unified Health System. Acta Cirurgica Brasileira. 2010; 25(2):201-05.

24. Santo MA, Pajecki D, Riccioppo D, Cleva R, Kawamoto F, Cecconello I. Early complications in bariatric surgery: incidence, diagnosis and treatment. Arq Gastroenterol 2013; 50(1):50-55.

25. Smith FJ, Holman CDJ, Moorin RE. Incidence of bariatric surgery and postoperative outcomes: a population-based analysis in Western Australia. Med J Aust 2008; 189 (4): 198-202.

26. Smith MD, Patterson E, Wahed AS, et al. Relationship between surgeon volume and adverse outcomes after RYGB in Longitudinal Assessment of Bariatric Surgery (LABS) study. Surg Obes Relat Dis. 2010; 6(2):118-25.

27. Sturm R, Hattori A. Morbid obesity rates continue to rise rapidly in the US. Int J Obes 2013; 37(6):889-91.

28. Wadden TA, Butryn ML, Wilson C. Lifestyle modification for the management of obesity. Gastroenterology. 2007;132:2226-38.

29.Zhang W, Mason EE, Renquist KE, Zimmerman MB, Contributors I. Factors influencing survival following surgical treatment of obesity. Obes Surg. 2005;15(1):43-50.

30.Zilberstein B, Halpern A, Silva MM, et al. Waiting time for bariatric surgery in a public hospital in Brazil. a problem to be solved [abstract]. Obesity Surgery; 2006; 16:1023. 